\title{
RELACIONES DE LOS PROCESOS DE INTEGRACIÓN DE AMÉRICA LATINA CON LA UNIÓN EUROPEA, ENTRE EL DIÁLOGO POLÍTICO, LOS PROGRAMAS DE COOPERACIÓN Y LOS ACUERDOS COMERCIALES
}

\author{
RELATIONS OF THE INTEGRATION PROCESSES BETWEEN LATIN AMERICA AND \\ THE EUROPEAN UNION, POLITICAL DIALOGUE, COOPERATION PROGRAMS AND \\ TRADE AGREEMENTS
}

\author{
Ana María Suárez Romero \\ Karina Lilia Pasquariello Mariano
}

\begin{abstract}
RESUMEN
La Unión Europea (UE) se ha afianzado como un actor político internacional en el escenario mundial, por lo cual necesita socios que le ayuden a promover relaciones internacionales basadas en su Política Exterior y de Seguridad Común, además de mantener diálogos sobre políticas económicas, comerciales y de desarrollo, entre otras. Por estas razones, la UE ha considerado esencial consolidar una asociación estratégica con América Latina, convirtiéndose en el inversionista extranjero más grande de la región, uno de los principales donantes e importante socio comercial. Este artículo discutirá cómo han sido las relaciones de tres procesos de integración: Comunidad Andina, MERCOSUR y la Alianza del Pacífico con la UE. En este sentido, el análisis parte de la discusión de la Asociación Estratégica UE-América Latina y la visión de los tres bloques latinoamericanos sobre la UE como socio estratégico, el histórico de sus acercamientos y los avances en los acuerdos establecidos.
\end{abstract}

\section{PALABRAS CLAVE}

Comunidad Andina, Alianza del Pacífico, MERCOSUR, Unión Europea, Asociación Estratégica.

\section{ABSTRACT}

The European Union (EU) has established itself as an international political actor on the world stage, which is why it needs partners to help it promote international relations based on a Common Foreign and Security Policy, in addition to holding dialogues on economic, commercial and development policies, among others. For these reasons, the EU has considered it essential to consolidate a Strategic Partnership with Latin America, becoming the largest foreign investor in the region, one of the main donors and an important trading partner. This article will discuss how the relations of three regional integration processes have been: Andean Community, MERCOSUR and the Pacific Alliance with the EU. In this sense, the analysis starts from the discussion of the EU-Latin American Strategic Partnership and the vision of the three Latin American blocs about the EU as a strategic partner, the

\footnotetext{
* El presente trabajo fue realizado con el apoyo de la Coordinación de Perfeccionamiento de Personal de Nivel Superior - Brasil (CAPES) - Código de Financiación 001. La versión preliminar de este artículo fue presentada en el I Congreso Latinoamericano de Integración Regional y Desarrollo Sostenible - GRIDALE, que se desarrolló en la ciudad de Bogotá - Colombia los días 21 y 22 de junio de 2018.
} 
Relaciones de los procesos de integración de América Latina con la Unión Europea, entre el diálogo político, los programas de cooperación y los acuerdos comerciales. DOI: https://doi.org/10.24215/24689912e031

history of their approaches and the progress in the established agreements.

\section{KEYWORDS}

Andean Community, Pacific Alliance, MERCOSUR, European Union, Strategic Partnership. 


\section{INTRODUCCIÓN}

La Unión Europea (UE) es el modelo de cooperación e integración regional con mayor reconocimiento y éxito en el entorno mundial, avanzando hasta consolidar un mercado interno sólido y una moneda común entre la mayor parte de sus 27 estados miembros. Por sus características propias y los procesos desarrollados por la organización, esta experiencia no puede ser aplicada en las mismas condiciones en otras iniciativas regionales de integración, pero se considera como un modelo de referencia.

La estructura de las relaciones internacionales de la UE adquirió mayor relevancia con la Política Exterior y de Seguridad Común (PESC) ${ }^{1}$, creada con los objetivos de preservar la paz, reforzar la seguridad internacional, fomentar la cooperación internacional con terceros países, desarrollar y consolidar la democracia y el Estado de Derecho, al igual que el respeto de los derechos humanos y las libertades fundamentales. Desde su creación, la PESC se ha fortalecido con los diferentes tratados constitutivos y de fortalecimiento institucional de la $U^{2}$, lo que ha impulsado asociaciones y diálogos políticos, basados en intereses y beneficios recíprocos, del bloque europeo con los principales actores internacionales al igual actividades diplomáticas y de cooperación como las Cumbres con países con los que la UE mantiene una Asociación Estratégica, además de diversos encuentros en distintos niveles con países y organismos regionales de los diferentes continentes.

En el presente artículo se describe cómo se ha desarrollado la Asociación Estratégica UEAmérica Latina y en qué medida el bloque europeo sigue manteniendo su influencia en la región, analizando su relación con tres bloques subregionales: Comunidad Andina (CAN), Mercado Común del Sur (MERCOSUR) y Alianza del Pacífico (AP). Mediante una investigación documental-descriptiva y cuantitativa-analítica, son abordados en forma general los procesos de negociación de los Acuerdos de Asociación Estratégica propuestos por la UE con cada bloque latinoamericano, haciendo énfasis en el intercambio comercial

\footnotetext{
${ }^{1}$ La Política Exterior y de Seguridad Común (PESC) de la UE se creó en 1993 en virtud del Tratado de Maastricht o Tratado de la Unión Europea (TUE), con este acuerdo se constituyó la UE y estableció su estructura en tres categorías o pilares: la Comunidad Europea (primer pilar), la PESC (segundo pilar), y la Cooperación policial y judicial en materia penal (tercer pilar). Esta estructura prevaleció hasta el 2009 con la entrada en vigor del Tratado de Lisboa. Ver: https://www.europarl.europa.eu/factsheets/es/sheet/3/los-tratados-de-maastricht-y-amsterdam 2 Ver https://www.europarl.europa.eu/factsheets/es/sheet/158/la-politica-exterior-objetivosmecanismos-y-resultados
} 
(exportaciones e importaciones entre los años 2002-2019) entre cada bloque -CAN y MERCOSUR- y por país -en el caso de la AP-, con la UE, los Estados Unidos (en adelante EUA) como socio comercial tradicional de la región y China que en los últimos años ha pasado de ser un actor marginal a ser un importante socio comercial y actor económico, especialmente como inversor directo en América Latina.

El supuesto de este trabajo es que la UE, buscando reforzar su papel como modelo en el orden internacional y actor global, ha logrado establecer relaciones birregionales con los bloques de integración de ALC mediante una asociación estratégica centrada inicialmente en intereses comerciales, para posteriormente profundizar sus relaciones en asuntos económicos, de cooperación y políticos-diplomáticos. La primera parte del artículo describe la evolución de las relaciones birregionales entre la UE y ALC, su institucionalización y el establecimiento de la política de Asociación Estratégica Birregional. La segunda parte presenta cómo se han desarrollado las relaciones de la UE con la CAN, el MERCOSUR y la Alianza del Pacifico, enfatizando en el intercambio comercial y las convergencias entre los bloques en la profundización de sus relaciones bilaterales. Finalmente son presentadas las conclusiones.

Como actor político internacional y particularmente como socio externo de América Latina y el Caribe (ALC), tradicionalmente la UE ha apoyado la integración regional y las formas más amplias de regionalismo (Sanahuja, 2013), pese a que en los últimos años han surgido divergencias ideológicas que ponen en cuestión el espíritu comunitario de los países latinoamericanos. América Latina y Europa comparten intereses por la paz, la libertad y el bienestar económico, y tienen como meta común luchar contra el terrorismo internacional y el crimen organizado global, frenar la proliferación de armas de destrucción masiva y resolver pacíficamente los conflictos étnicos (Vogel, 2007, p. 8).

De acuerdo con Molina y Mata (2010, p.137), las relaciones entre la UE y ALC se han desarrollado en los ámbitos político-diplomático, económico-financiero y de la cooperación, representando intereses particulares para cada región. De acuerdo con los autores, ALC representa una asociación prometedora para la UE por su significado como partenariado estratégico en materia geopolítica y económica; profundizar sus relaciones representa una oportunidad de reforzar su papel como modelo en el orden internacional, ya que busca a través de los acuerdos birregionales fortalecer las razones para la construcción de bloques como instrumento de inserción en un mundo globalizado, A su vez, la UE representa para 
ALC un amplio y prometedor mercado y un socio estratégico en el ámbito de los debates internacionales, lo que le permite tener otra alternativa frente a la influencia de los EUA en la región.

Las relaciones birregionales entre la UE y ALC comenzaron a institucionalizarse desde la segunda mitad de los años noventa en lo que se conoce como las Cumbres UE-ALC ${ }^{3}$; son reuniones bienales de alto perfil en las que jefes de Estado y de Gobierno dialogan en diferentes aspectos para consolidar una comunidad birregional basados en un pasado compartido y en valores e intereses comunes. Cada cumbre se desarrolla en el marco de los acuerdos previos alcanzados en la escena política y se define un tema específico.

La primera cumbre se desarrolló en Río de Janeiro en 1999; desde entonces la UE y ALC participan en una política de Asociación Estratégica ${ }^{4}$. Esta Asociación Estratégica busca consolidar un modelo socioeconómico en el que la transferencia de conocimiento, la educación y el desarrollo sostenible acerquen a los países y regiones, con los objetivos de reducir los niveles de pobreza y la exclusión política, además de alinear a la UE y a ALC como regiones socias (Fundación EU-LAC, 2017, p.6).

La Asociación Estratégica Birregional se diferencia de otros procesos de integración en la medida que busca establecer más que una asociación económico-comercial entre las dos regiones. Para poder alcanzar esta diferencia la estrategia se fundamenta en tres pilares: la intensificación del diálogo político, el refuerzo de la cooperación especialmente en las áreas económica y cultural, y la intensificación de las relaciones comerciales.

La creación de la Asamblea Parlamentaria Euro-Latinoamericana (EuroLat) en 2006 respondió a la necesidad de establecer una nueva Agenda Política Birregional, centrada en temas relacionados con la gobernanza y la consolidación de la democracia y sus instituciones. Actualmente la Asamblea cuenta con 150 miembros ${ }^{5}$ representando por partes iguales al Parlamento Europeo y a los diferentes parlamentos regionales de América Latina, de México y Chile (Parlamento de la Comunidad Andina, Parlamento Centroamericano,

\footnotetext{
${ }^{3}$ El proyecto de la Comunidad de Estados Latinoamericanos y Caribeños (CELAC) se materializó en 2011, desde entonces la organización representa a 33 países de América Latina y el Caribe en la interlocución con la UE en las Cumbres birregionales de alto nivel pasando a ser llamada Cumbre CELAC-UE. La primera se desarrolló en Santiago de Chile en el año 2013.

${ }^{4}$ Término que hace referencia a un instrumento de la política exterior de la Unión Europea que busca fortalecer su relación con terceros países o regiones.

${ }^{5}$ Los miembros de la EuroLat son designados de acuerdo con las reglas de cada Parlamento. Ver: Asamblea Parlamentaria Euro-Latinoamericana.
} 
Parlamento Latinoamericano, Parlamento del Mercado Común del Sur - MERCOSUR, Congreso de México y Congreso de Chile).

También ha sido importante el apoyo facilitado por la UE a diversas agendas políticas de ALC como la lucha contra las drogas ilícitas, el perfeccionamiento de políticas públicas (especialmente las orientadas a las cuestiones de género, democracia, pobreza, educación y racismo), apoyo a proyectos ambientales y al fortalecimiento institucional, este último muy vinculado a las estructuras administrativas de los bloques regionales (Sanahuja, 2013).

El volumen de la ayuda europea para ALC es significativo. En el plano estratégico establecido por la Comisión Europea para el período 2002-2006 se destinaron 264 millones de euros para financiar este programa de asociación. Para el período siguiente (2007 a 2013) el volumen de recursos se duplicó, pasando a 556 millones de euros que por supuesto no se distribuyen igualitariamente entre los países de la región, pero indican una fuerte relación de asociación entre la UE y ALC.

Sin embargo, las relaciones comerciales siguen siendo un punto central en la asociación, especialmente por el interés europeo de convertirse en un importante socio comercial de la región. En nuestro análisis es posible percibir que a medida que se intensifican las negociaciones comerciales, los aspectos relacionados al diálogo político pierden relevancia en las relaciones entre los bloques. En este caso, se enfrenta a la competencia norteamericana, ya que EUA ha sido tradicionalmente el principal socio comercial con gran influencia en la región y más recientemente de China que ha ampliado su presencia redireccionando el foco de atención de los países americanos hacia la región del Pacífico.

\section{El inTERREgIONALISMO ENTRE LA UNIÓN EUROPEA Y AMÉRICA LATINA}

La UE se ha consolidado como una asociación económica y política de referencia en el contexto de la integración regional, por lo cual ha sido objeto de estudio de académicos y especialistas en el área, los cuales intentan examinar el proceso de integración en sí mismo y la forma cómo se relaciona con el mundo. En este sentido, la relación de la UE con ALC ha sido analizada por diversos autores (Müller et al., 2017; Parra, 2010; Quevedo, 2007; Sanahuja, 2006, 2013; Serbin y Serbin Pont, 2018), lo cual ha permitido establecer referentes conceptuales para la observación y análisis de la estrategia interregional europea y su influencia en la integración regional latinoamericana. 
Una característica distintiva en la actuación internacional de la UE ha sido el apoyo a la promoción de la integración regional y a otras formas más amplias de regionalismo (Sanahuja, 2013). El apoyo a la integración latinoamericana por parte de la UE se enmarca en una combinación no siempre perfecta de intereses, valores e identidades. Estos aspectos han sido descritos por Sanahuja (2013): para el autor se interpreta el interés del bloque europeo en los procesos de integración como un mecanismo de acceso a mercados más amplios, además de una herramienta para promover el crecimiento económico y la estabilidad política y contar con el respaldo de aliados internacionales permitiendo un marco de certidumbre y seguridad jurídica para los inversionistas europeos en la región. Por otra parte, los valores -que han sustentado la UE desde su creación y que son promovidos en su acción exterior- como las aspiraciones de paz, el desarrollo, la democracia y los derechos humanos, pueden ser promovidos y articulados a través de la integración regional. Por último, las identidades que representan los dos bloques en la medida que ALC y la UE, pese a que se configuran como actores diferenciados en el sistema internacional, se aproximan en cuanto a su adhesión a principios y valores democráticos, y a los derechos humanos.

La forma como la UE ha desarrollado sus relaciones exteriores, especialmente desde la implementación de la PESC y la consolidación de Asociaciones Estratégicas, se clasifica en cuatro categorías: la primera de ampliación del mismo bloque; la segunda de vecindad, con la cual los países que no están interesados en hacer parte del bloque buscan mejorar sus relaciones encontrando ventajas de su asociación; la tercera categoría hace referencia al bilateralismo estratégico, donde la UE busca relacionarse con países desarrollados y con mayor influencia global, como por ejemplo Estados Unidos y Rusia. La última categoría llamada de interregionalismo, en la que la UE negocia con otras regiones del mundo buscando profundizar en la cooperación comercial, económica y el dialogo político.

El interregionalismo, que es definido como el estrechamiento institucionalizado de las relaciones entre regiones en el mundo (Hänggi et al, 2006), surgió como fenómeno en la economía política internacional y, pese a que en los años setenta la UE comenzó a impulsar sus relaciones exteriores con otros grupos con el interés de ampliar su papel como actor internacional, fue a mediados de la década de los noventa que se impulsaron nuevas formas de relaciones interregionales. Se le puede percibir como una extensión de las estrategias del nuevo regionalismo o del regionalismo abierto, que adoptaron actores estatales y no estatales en el contexto de la globalización desde del fin de la Guerra Fría. 
De acuerdo con lo anterior, las relaciones de la UE y ALC se han enmarcado en la categoría del interregionalismo, en la medida que el apoyo a la integración y el regionalismo también ha respondido a la percepción europea de que ALC necesita grupos regionales que le brinden herramientas y contribuyan para su propia gobernanza y desarrollo, y que además promuevan a la UE como actor global.

La estrategia interregional de la UE para ALC fue trazada a mediados de los años noventa y en términos generales su objetivo ha sido:

Promover el regionalismo y la integración regional a través de una "red" de acuerdos de asociación, que habrían de firmarse con todos los países y grupos conforme al "mapa" del regionalismo latinoamericano, tal y como se gestó a principios de los años noventa. Esa estrategia partió del supuesto de que tanto el diálogo político birregional, como la posibilidad de suscribir Acuerdos de Asociación, deberían actuar como condición o incentivo para la mejora de la cooperación y la profundización de la integración en ambas partes (Sanahuja, 2013, p.160).

De acuerdo con Ayuso et al. (2018) "el regionalismo y el interregionalismo han constituido un patrón de relacionamiento entre ALC y la UE" (p. 9) y desde la institucionalización de las relaciones de los dos bloques en los años noventa, la implementación de la estrategia interregional ha enfrentado obstáculos y dificultades, lo que se explica por la heterogeneidad de los actores y las coyunturas regionales. Para el caso de la UE los innumerables desafíos de los últimos años, como la crisis económica internacional de 2008, la crisis migratoria, el aumento de movimientos eurocépticos y más recientemente el proceso de negociación de la salida del Reino Unido del bloque europeo, conocido como Brexit.

Por el lado de ALC, también fracciones en los diferentes procesos de integración, como la parálisis y posterior desaparición de la Unión de Naciones Suramericanas (Unasur) y en su contraparte la creación del Foro para el progreso e Integración de América del Sur (Prosur), la crisis económica y política de Venezuela, además del estancamiento y crisis de algunos grupos de integración como la CAN y el MERCOSUR, cuyas relaciones con la UE serán detalladas a continuación. 


\section{Comunidad Andina (CAN)}

El esquema de integración de la CAN resalta en ALC por su antigüedad, por lo cual ha tenido una atención especial por parte de la UE debido a las expectativas que genera la construcción de relaciones basadas en el regionalismo abierto (Gómez, 2015). Los vínculos birregionales se han basado en la cooperación, las relaciones comerciales y el diálogo político.

En la evolución de la cooperación birregional se identifican cuatro etapas en las cuales se han creado diferentes mecanismos para satisfacer intereses comunes. La primera etapa se desarrolló desde 1973 a 1982 y se basó en la cooperación regional para países en desarrollo (PED-ALA) con enfoque estrictamente bilateral para promover el desarrollo agropecuario, la cooperación energética y la agricultura, además de la implementación del Sistema Generalizado de Preferencias (SGP) para Países en Desarrollo. La firma del Acuerdo de Cooperación de segunda generación marcó el inicio de la segunda etapa (desde 1983 a 1992), convirtiendo al entonces Pacto Andino en el primer bloque en suscribir un acuerdo de esa naturaleza con la UE. En 1991 se implementó el SGP-Andino (también llamado SGP Droga), con el cual la mayor parte de sus exportaciones industriales, algunas pesqueras y agrícolas, podían ingresar al mercado de la UE libres de arancel.

EI SGP-Andino como mecanismo de reducción unilateral de aranceles era una respuesta a la lucha contra las drogas ilícitas y se enmarca en los ejes temáticos de la agenda europea, con lo cual se promovió un acercamiento con la CAN basado en "Responsabilidad Compartida" interregional dado que la Región Andina tiene los principales países productores de drogas ilícitas y la UE alberga países consumidores de estas.

EI SGP-Andino tenía una vigencia inicial de cuatro años por lo que fue renovado en varias ocasiones hasta el año 2004; en este año algunos países, especialmente la India, criticaban ante la Organización Mundial de Comercio (OMC) la prórroga del SGP al considerar que la lucha contra la producción de drogas no era motivo suficiente para discriminar a otros países que compiten en el mercado común europeo. EI SGP fue revisado y adecuado de acuerdo con los cuestionamientos de la OMC adoptando el Régimen Especial de Estímulo del Desarrollo Sostenible y la Gobernabilidad (SGP-Plus) a partir del año 2006.

En la tercera etapa (1993-2003) se firmó el Acuerdo Marco de Cooperación (1993), denominado de tercera generación, el cual abordaba la profundización y consolidación de un 
proceso de integración birregional que complementa las acciones bilaterales de la UE con los países andinos en el desarrollo de sectores productivos, comercio, inversiones y tecnología, disminuyendo el carácter notoriamente asistencialista que hasta entonces habían marcado las relaciones birregionales. Este Acuerdo, sumado al Mecanismo de Diálogo Político implementado desde la Declaración de Roma en 1996, constituyen el marco institucional de la relación birregional, los dos orientados a sostener la integración económica regional y la lucha en contra del narcotráfico con un "diálogo especializado de alto nivel sobre drogas" (Leví, 2010, p. 251).

En la negociación del Acuerdo de Diálogo Político y de Cooperación (2003) se incluyeron otros objetivos relacionados con la PESC de la UE, en los que se destacan la cohesión social y económica, institucionalización del diálogo político, migración, prevención de conflictos, buen gobierno y contra el terrorismo. En el proceso de negociación de este acuerdo se establece la necesidad de crear un nuevo marco de relaciones entre los dos bloques, el cual implicaría sustituir el régimen SGP por un Acuerdo de Libre Comercio permanente con la UE considerando las asimetrías de los bloques y conforme a las reglas de la OMC.

De acuerdo con Leví (2010) el mecanismo de diálogo político permanente establecido en las cumbres de UE-ALC desarrolladas entre 1999 y 2008, generó que en las reuniones de alto nivel tomara fuerza la consolidación del Acuerdo de Asociación Estratégica UE-CAN (de cuarta generación), sobre la base de bloque a bloque con el objetivo de apoyar y fortalecer el proceso de integración andino.

Los Acuerdos de Asociación que la UE negocia a nivel bilateral poseen una estructura principal pero el modo en que se conducen las negociaciones es diferente para cada caso y responde a las condiciones particulares que presenta cada país o bloque (Leví, 2010). Las negociaciones del Acuerdo UE-CAN se desarrollaron entre el 2006-2008, pero de acuerdo con Leví (2010) y Sanahuja (2013) las crecientes diferencias de visión económica entre sus miembros, la prioridad a los temas comerciales en las rondas de negociación y la falta de atención por parte de la UE a los cambios de regímenes políticos de Ecuador y Bolivia, fueron algunos de los factores que limitaron y bloquearon las negociaciones. Bolivia abandonó las negociaciones en el 2008 marcando la crisis del proceso del Acuerdo UECAN, y a la vez del mismo proceso de integración andino. 
En respuesta a la crisis en las negociaciones del Acuerdo de Asociación birregional, a partir del 2009 la UE decidió proponer a los países de la CAN un acuerdo multipartes de comercio pasando a una negociación bilateral, abandonando la negociación interregional en lo referido al componente comercial del acuerdo, pero manteniendo el diálogo político y la cooperación al desarrollo en el ámbito birregional (Sanahuja, 2013). Colombia y Perú aceptaron firmar el acuerdo de libre comercio propuesto por la UE y, tras varias rondas de negociaciones comerciales, el acuerdo ${ }^{6}$ fue firmado por los dos países el 26 de junio de 2012, entrando en vigor con carácter provisional el 1 de marzo de 2013 en Perú y desde el 1 de agosto de 2013 en Colombia.

Por su parte, Ecuador había suspendido su participación en las negociaciones en julio de 2009, posteriormente en 2010 decidió retomar los acercamientos con la UE bajo un "pacto para el desarrollo sobre el comercio, temas no comerciales, diálogo político y cooperación" (El Telégrafo, 2016, párr. 24). En 2016 se firmó el Protocolo de Adhesión de Ecuador al Acuerdo Comercial con Colombia y Perú, entrando en vigor con carácter provisional el 1 de enero de $2017^{7}$.

La relación comercial entre ambos bloques data de hace cuatro décadas; a partir del año 2001 las exportaciones de la CAN a la UE han crecido sosteniblemente (gráfica 1) convirtiéndose en el segundo socio comercial de los países andinos después de EUA, y una significativa fuente de inversiones especialmente para Colombia y Perú (Fairlie, 2010). Durante este periodo las exportaciones presentaron una leve caída en el año 2009 por causa de la crisis internacional retomando su dinámica de crecimiento en el siguiente año. En cuanto a las importaciones con origen de la UE, como se observa en la gráfica 2, hasta el 2009 ocuparon el segundo lugar y a partir del 2010 fueron sobrepasadas por las importaciones de origen chino.

Cabe resaltar la importancia que China ha adquirido como socio comercial de los países andinos. Como será presentado en los otros bloques de integración analizados en este trabajo, el país asiático ha surgido como una fuerza importante en la economía mundial, convirtiéndose en un significativo competidor en los mercados de productos industriales y

\footnotetext{
${ }^{6}$ Ver: Acuerdo Comercial entre la Unión Europea y sus Estados miembros, por una parte, y Colombia y el Perú, por otra.

${ }^{7}$ Ver: Notificación relativa a la aplicación provisional entre la Unión Europea y la República del Ecuador del Protocolo de Adhesión del Acuerdo Comercial entre la Unión Europea y sus Estados miembros, por una parte, y Colombia y el Perú, por otra, para tener en cuenta la adhesión de Ecuador, Diario Oficial de la UE.L 358/1 de 29.12.2016.
} 
ascendido como principal socio comercial de varios países de ALC. En lo que respecta a la CAN, China se ubica como el segundo destino de las exportaciones a partir del año 2017, logrando duplicar su valor en el año 2019 y, en cuanto a las importaciones a partir del año 2010, representa el segundo país de origen acercándose a las cifras de EUA al duplicar su valor en el año 2019 (gráfica 2). Tradicionalmente EUA ha sido el principal socio comercial de la CAN, lo que se explica en parte por los beneficios concedidos a los países andinos del SGP del país del norte y los tratados de libre comercio con Colombia, Perú y Ecuador.

\section{Gráfica 1. Exportaciones totales de la CAN hacia la Unión Europea, China y Estados Unidos,} años 2002-2019

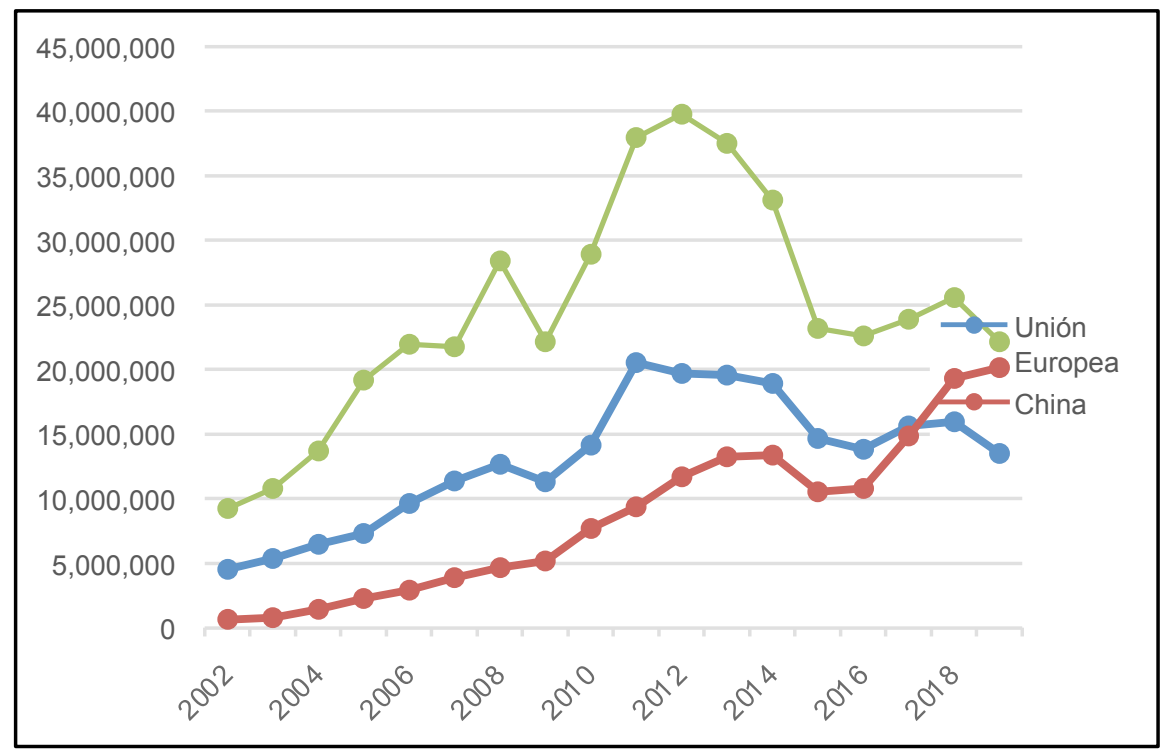

*Valores en miles de US\$

Fuente: Elaboración propia a partir de información del Sistema de Información de Comercio Exterior (SICOEX) - ALADI. 
Gráfica 2. Importaciones totales de la CAN desde la Unión Europea, China y Estados Unidos, años 2002-2019

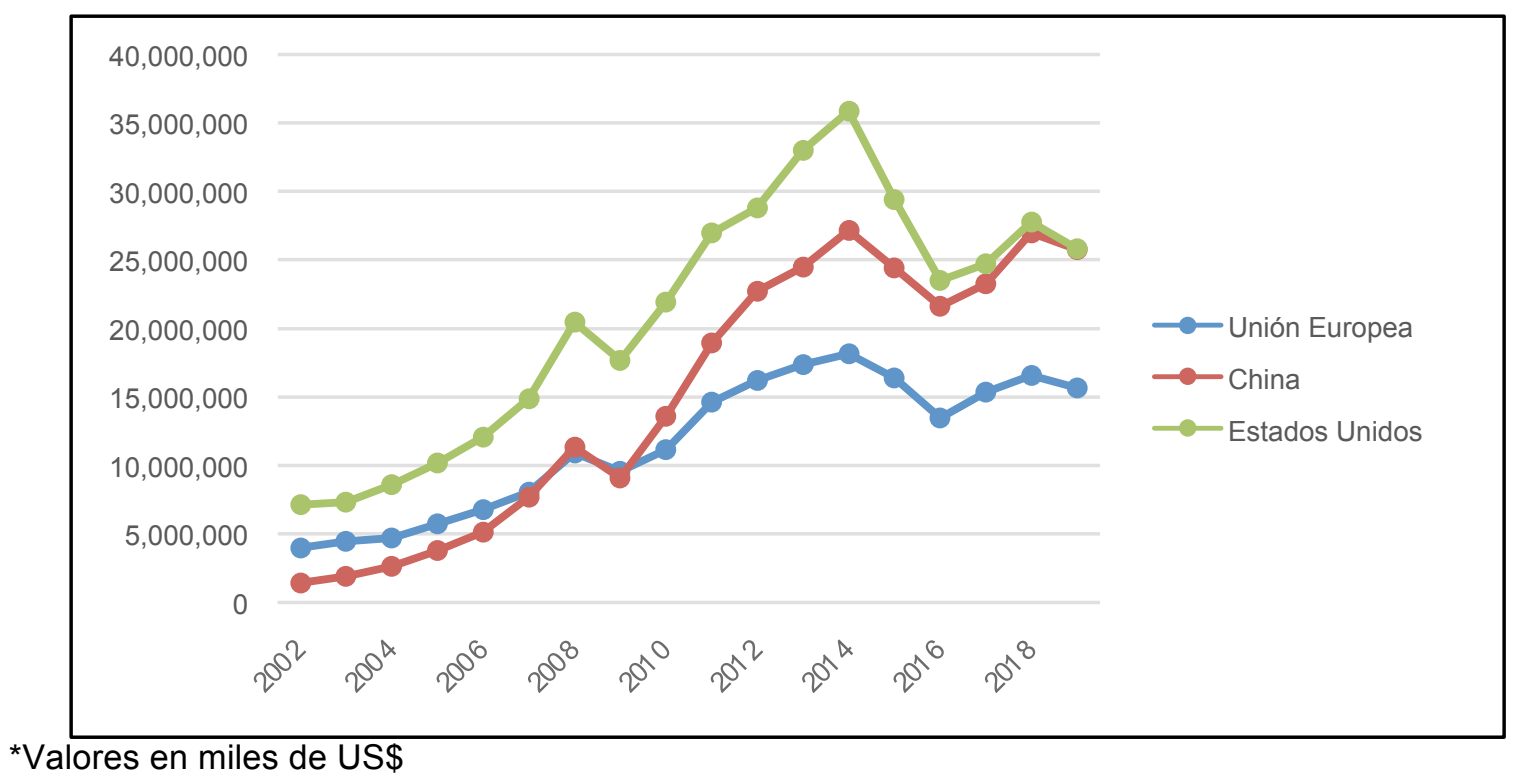

Fuente: Elaboración propia a partir de información del Sistema de Información de Comercio Exterior (SICOEX) - ALADI.

La debilidad institucional de la CAN ha sido el principal obstáculo para que la UE pueda consolidar una estrategia interregional, dado que la poca coordinación y armonización interna dificultan las negociaciones y crean ambientes tensos que no permiten avanzar en los objetivos propuestos (Gómez, 2015). La opción por seguir una lógica bilateral de negociación intensificó la atención en los aspectos comerciales.

Las dificultades presentadas en las negociaciones en bloque con la CAN han generado que la UE centre su atención en relaciones que le puedan ofrecer una mayor cobertura geográfica y reducción de costos de negociación, como son el MERCOSUR, el SICA (Sistema de Integración Centroamericana) y la CELAC.

\section{MeRCAdo Común del SUR (MERCOSUR)}

La UE buscó aproximarse al MERCOSUR desde su inicio, buscando apoyar esta iniciativa tanto políticamente como fortaleciendo los lazos de cooperación comercial con el nuevo bloque, firmando en mayo de 1992 el Acuerdo de Cooperación Interinstitucional entre la Comunidad y el MERCOSUR, el cual garantizó el apoyo europeo a la consolidación 
institucional del nuevo bloque y fue importante en la ampliación de su institucionalidad, como en la creación del Parlamento del MERCOSUR (Parlasur) por ejemplo.

Ese apoyo inicial permitió que la entonces Comunidad Económica Europea (CEE) fortaleciera también sus relaciones comerciales con la región aumentando en más del $40 \%$ las exportaciones para el MERCOSUR entre los años 1992-1993 (Bispo, 2018). Ante este escenario propicio, ganó fuerza dentro de la estructura comunitaria la propuesta de implementar un acuerdo de cooperación comercial con el MERCOSUR, a pesar de algunas resistencias y de la desconfianza sobre la estabilidad del nuevo bloque por dos motivos principales: éste aún estaba en un período de transición (construyendo tanto su agenda de negociación, como su propia institucionalidad), sumado a las inestabilidades políticas y económicas de los países que estaban consolidando su redemocratización y buscando salidas para la crisis económica que azotó la región al final de los años 1980.

Estas desconfianzas fueron amenizadas a medida que el bloque suramericano se consolidó con el Protocolo de Ouro Preto (1994) que estableció la institucionalidad de la unión aduanera -y de la Tarifa Externa Común (TEC)- y con los resultados positivos de implementación de los planes económicos de convertibilidad en Argentina (Plan Austral de 1991) y en Brasil (Plan Real de 1994) que estabilizaron las principales economías de la región.

Además de estos factores internos, otros dos elementos fueron importantes para estimular la aproximación comercial de la UE al MERCOSUR: el primero, la propuesta hecha al final de 1994 por el gobierno norte-americano de Bill Clinton de establecer el Área de Libre Comercio de las Américas (ALCA), lo que implicaría la consolidación de la influencia de los EUA en la región; el segundo está relacionado con la conclusión de la Ronda de Uruguay del Acuerdo General de Tarifas y Comercio (GATT, del inglés General Agreement on Tariffs and Trade), la creación en 1994 de la Organización Mundial de Comercio que apuntaba para un escenario de mayor liberalización comercial, y el fin de los subsidios que era un tema sensible para el bloque europeo en el ámbito agrícola (Cavalcanti y Trein, 2007).

Ante estos nuevos contextos regionales y mundiales, la UE decidió llevar a cabo el proyecto de aproximación comercial con el MERCOSUR, lo que resultó a finales de 1995 con el Acuerdo-Marco de Cooperación Interregional firmado en Madrid y que tenía como objetivo final establecer una asociación interregional entre los dos bloques regionales, con la liberación recíproca y progresiva de todo el comercio (Acordo-Quadro inter-regional de 
coperação, 1995). Desde el año 2000 la UE y el MERCOSUR iniciaron las negociaciones para establecer un área de libre comercio birregional; el acuerdo comprende tres áreas: un diálogo político, temas económicos y comerciales, y cooperación (Sistema de Información sobre Comercio Exterior-SICE, 2020).

Después de más de 20 años de negociaciones, el MERCOSUR concluyó el 28 de junio de 2019 el Acuerdo de Asociación Estratégica con la UE (MERCOSUR, 2019). Un aspecto interesante que podría explicar parcialmente el interés por ambas partes para continuar con el proceso de negociación pese a las dificultades y el tiempo transcurrido fue que la UE se tornó a partir de 2006 el principal destino de las exportaciones del MERCOSUR (ver gráfica 4) y era el principal origen de las importaciones hechas por el bloque del Cono Sur (ver gráfica 3). Fue a partir de 2015 que esa situación comercial comenzó a alterarse y China pasó a ser el principal destino de las exportaciones del MERCOSUR y a tener la misma importancia de Europa para sus importaciones.

La gráfica 3 muestra una importante alteración en las últimas décadas en las importaciones del MERCOSUR: en el inicio del siglo XXI había un cierto equilibrio entre UE y los EUA, en cuanto China tenía un rol bastante reducido. En tanto, a partir de 2010 hubo una inversión en las posiciones con las importaciones de origen chino ultrapasando las norteamericanas y aproximándose a las europeas, sobrepasándolas a partir del año 2018. La gráfica 4 - sobre las exportaciones del MERCOSUR para UE, China y EUA- muestra claramente ese crecimiento chino, en cuanto el principal aliado comercial del bloque. 


\section{Gráfica 3. Importaciones totales de MERCOSUR desde la Unión Europea, China y Estados} Unidos, años $2002-2019$

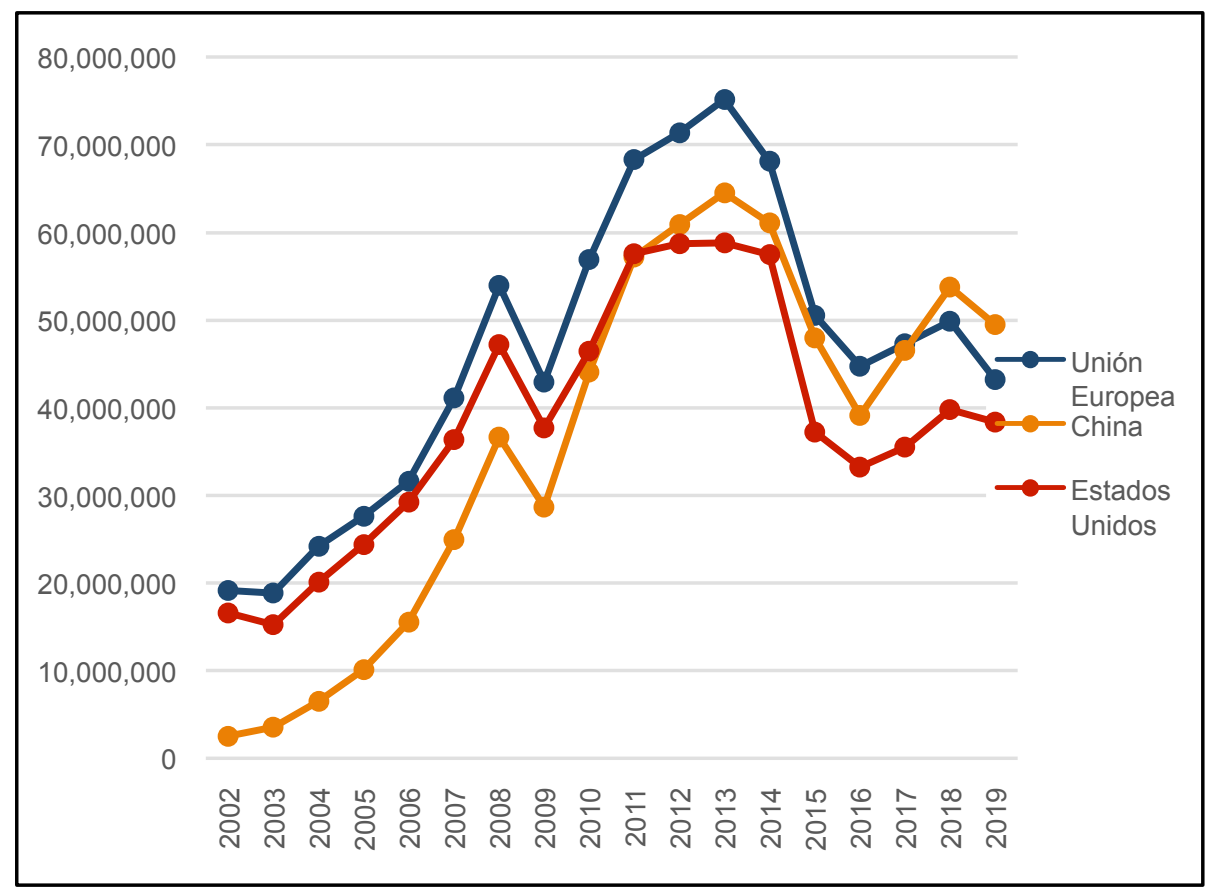

*Valores en miles de US\$

Fuente: Elaboración propia a partir de información del Sistema de Información de Comercio Exterior (SICOEX) - ALADI.

Gráfica 4. Exportaciones totales de MERCOSUR hacia la Unión Europea, China y Estados Unidos, años 2002-2019

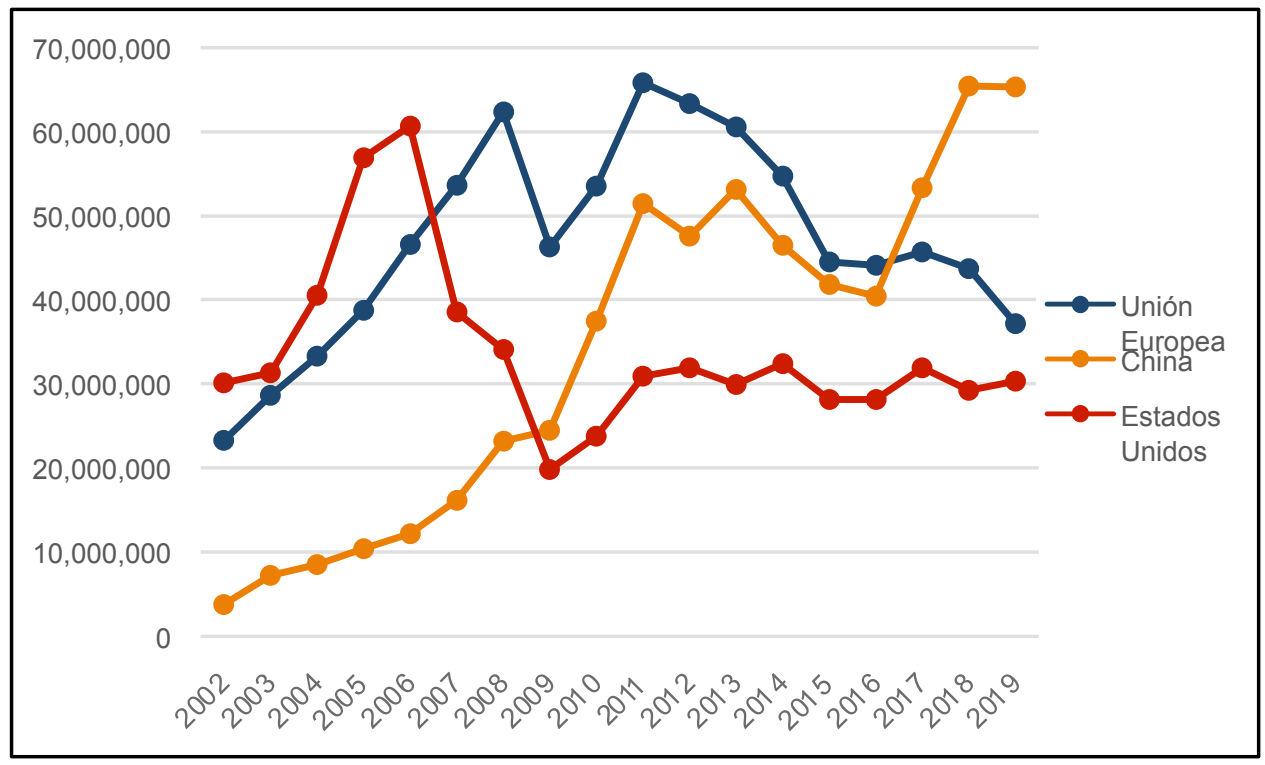

*Valores en miles de US\$

Fuente: Elaboración propia a partir de información del Sistema de Información de Comercio Exterior (SICOEX) - ALADI. 
En el proceso de negociación de la Asociación Estratégica birregional, ante el contexto comercial y de los cambios políticos en Argentina y Brasil a partir de 2016, con el ascenso de gobiernos con propuestas económicas más ortodoxas y favorables al establecimiento de acuerdos comerciales con mayor apertura comercial, hubo un nuevo estímulo para reanudar las negociaciones entre los dos bloques. Sin embargo, las resistencias de los sectores sensibles (especialmente europeos) se mostraron capaces de contener los avances de las negociaciones cuyo plazo para su conclusión fue constantemente postergado.

Aun así, es posible identificar algunos avances y resultados concretos en las relaciones entre el MERCOSUR y la UE, especialmente en lo que se refiere a la cooperación política entre los bloques. No obstante, esa alianza no fue suficiente para contener el avance de la influencia China en la región que de manera gradual está suplantando tanto a los EUA como a la UE como principal aliado comercial de esos países, e inversionista. Esa situación es favorecida por la actual estrategia comercial del gobierno norteamericano bajo la presidencia de Donald Trump, que al aplicar medidas más proteccionistas está facilitando el crecimiento de la importancia china en ALC y estimulando a la UE a fortalecer sus lazos comerciales con la región por medio de acuerdos comerciales.

Una vez finalizadas las negociaciones del acuerdo se inició el proceso de ratificación por las dos partes; de acuerdo con Pasquariello y Leite (2020) se esperaba que entre dos a tres años aproximadamente se podría iniciar la implementación del acuerdo considerando que la mayor dificultad estaría en ratificar el acuerdo en los 27 países miembros de la UE.

Por parte del MERCOSUR, el cambio político ocurrido con las elecciones presidenciales argentinas del 2019 y las declaraciones del presidente electo Alberto Fernández en cuanto a que, que podría revisar el acuerdo, estimularon la adopción de un nuevo principio dentro del bloque, el cual permite que la implementación del acuerdo se realice sin la necesidad de estar ratificado por todos los miembros si este fue ratificado por los pares europeos. Con esta medida, los demás gobiernos del MERCOSUR buscaron neutralizar la capacidad de veto del nuevo gobierno argentino garantizando viabilizar el acuerdo sin su anuencia.

Sin embargo, la ratificación del acuerdo está siendo retrasada no por resistencia argentina, sino por las tensiones políticas provocadas por el gobierno brasileño. Inicialmente, las declaraciones del presidente Jair Bolsonaro sobre la prioridad en establecer un acuerdo con el gobierno de Estados Unidos- y que esa negociación condicionaría la ratificación del 
acuerdo con la UE - estimularon críticas al gobierno de Brasil. Estas críticas se intensificaron por cuenta de la desastrosa política ambiental brasileña que desde 2019 ha intensificado los incendios en la Amazonia y la deforestación.

El pasado 6 de octubre el Parlamento Europeo en pleno aprobó una enmienda a un informe sobre la política común europea donde se consideró que el acuerdo negociado entre la UE y el MERCOSUR "no puede ser ratificado en su estado actual", respaldando su postura en las dudas generadas sobre el respeto de los países del Cono Sur a los compromisos y salvaguardas medioambientales del acuerdo. Desde que inició el proceso de ratificación por parte de los gobiernos europeos se han presentado resistencias enmarcadas en la acelerada deforestación en Brasil y las prevenciones de los agricultores europeos frente a la competencia desleal de empresas sudamericanas (La Nación, 2020).

\section{Alianza del Pacífico (AP)}

Diferente de las otras dos experiencias de regionalismo analizadas en este artículo, la AP es la que menos sufrió influencia del modelo europeo en lo que se refiere a su organización institucional. Creada en abril de 2011, la AP buscó desde el inicio consolidarse como una plataforma de articulación política y económica entre sus miembros -Chile, Colombia, México y Perú- para garantizar una mejor inserción en el sistema internacional.

Claramente alineado con los principios del regionalismo abierto, la AP propone como objetivo final el establecimiento de un bloque con libre circulación de bienes, servicios, capitales y personas que, aunque determine la consolidación de un mercado común, está mucho más vinculado a la lógica de una mayor liberalización. La construcción de un mercado común a los moldes europeos significaba el establecimiento de una institucionalidad con algún grado de autonomía y capacidad decisoria, además de la necesidad de una armonización de políticas macroeconómicas y reducción de las soberanías nacionales.

No hay en los documentos de ese bloque referencias de una intención de establecer una institucionalidad regional con esas características o atribuciones. Desde el inicio los gobiernos mantienen un discurso consistente de defensa de una baja institucionalidad estrictamente intergubernamental, así como su intención de concentrar la agenda de negociaciones en las cuestiones comerciales. Como apuntan Pasquariello y Correa (2017), 
el único espacio de participación de la sociedad es el Consejo Empresarial de la Alianza del Pacífico (CEAP), también orientado a discutir aspectos comerciales y económicos, que no pertenece formalmente a la estructura institucional de la AP pero que posee el apoyo del Comité de Expertos que analizan temas sugeridos por los sectores empresariales y elaboran propuestas que son enviadas al Grupo de Alto Nivel (GAN).

El caso de las relaciones UE-AP es particularmente interesante porque se diferencia de los otros dos analizados en este artículo, por ser un proyecto más reciente y con particularidades institucionales que chocan de las demás experiencias integracionistas de América Latina, desde los inicios de la AP la UE ha sido un estado observador (acompañado formalmente sus negociaciones y reuniones de cúpula) manteniéndose atenta a la evolución de este proceso.

En septiembre de 2019 las dos partes firmaron en Nueva York la Declaración Conjunta sobre una asociación entre los Estados Parte del Acuerdo Marco de la Alianza del Pacifico y la Unión Europea, con la cual se estableció un instrumento marco para fortalecer la cooperación y el diálogo entre los dos bloques en áreas como integración económica y financiera regional, educación y movilidad estudiantil, la lucha contra el cambio climático y crecimiento verde, estrategias digitales, la facilitación del movimiento de personas; así como la innovación, la ciencia y la tecnología (Alianza del Pacifico, 2019).

No existe hasta el momento la negociación de un acuerdo comercial entre los bloques, pero la UE posee tratados bilaterales con todos los países miembros de la AP: desde el año 2000 tiene un tratado de libre comercio con México; en 2002 firmó un Acuerdo de Asociación con Chile y en 2012, debido al fracaso de las negociaciones en el ámbito UE-CAN, la UE firmó Acuerdos Comerciales bilaterales con Colombia y Perú.

¿Esta situación permitiría una mayor importancia de la UE junto a la AP diferente de la que verificamos en los demás bloques analizados? O sea, ¿habría una disminución del peso de China entre las economías de esos países? ¿EUA continuaría siendo el principal aliado, especialmente considerando su proximidad con México?

Si analizamos los datos comerciales de importación y exportación de la AP con China, EUA y la UE, verificamos que EUA aún es el principal aliado comercial de este bloque pero esa participación no es equilibrada; esto es, es distorsionada por el peso de los cambios 
comerciales entre México y su aliado en el USMCA ${ }^{8}$ (United States, Mexico and Canada Agreement), y por el peso que la alianza norteamericana aún posee con Colombia, como demuestran las gráficas a continuación.

En lo que se refiere a las exportaciones (Gráfica 5), México es el único país de la AP en el que China no ocupa los dos primeros lugares como socio comercial. En este caso, podemos constatar que tanto el USMCA como el Tratado de Libre Comercio con la UE lograron mantener el nivel de importancia. En el caso contrario, los datos referentes a las importaciones (Gráfica 6) demuestran un ascenso consistente de China, colocándose como el segundo país de origen de las importaciones mexicanas.

\section{Gráfica 5. Exportaciones totales de México hacia China, Estados Unidos y la Unión Europea,} años $2002-2018$

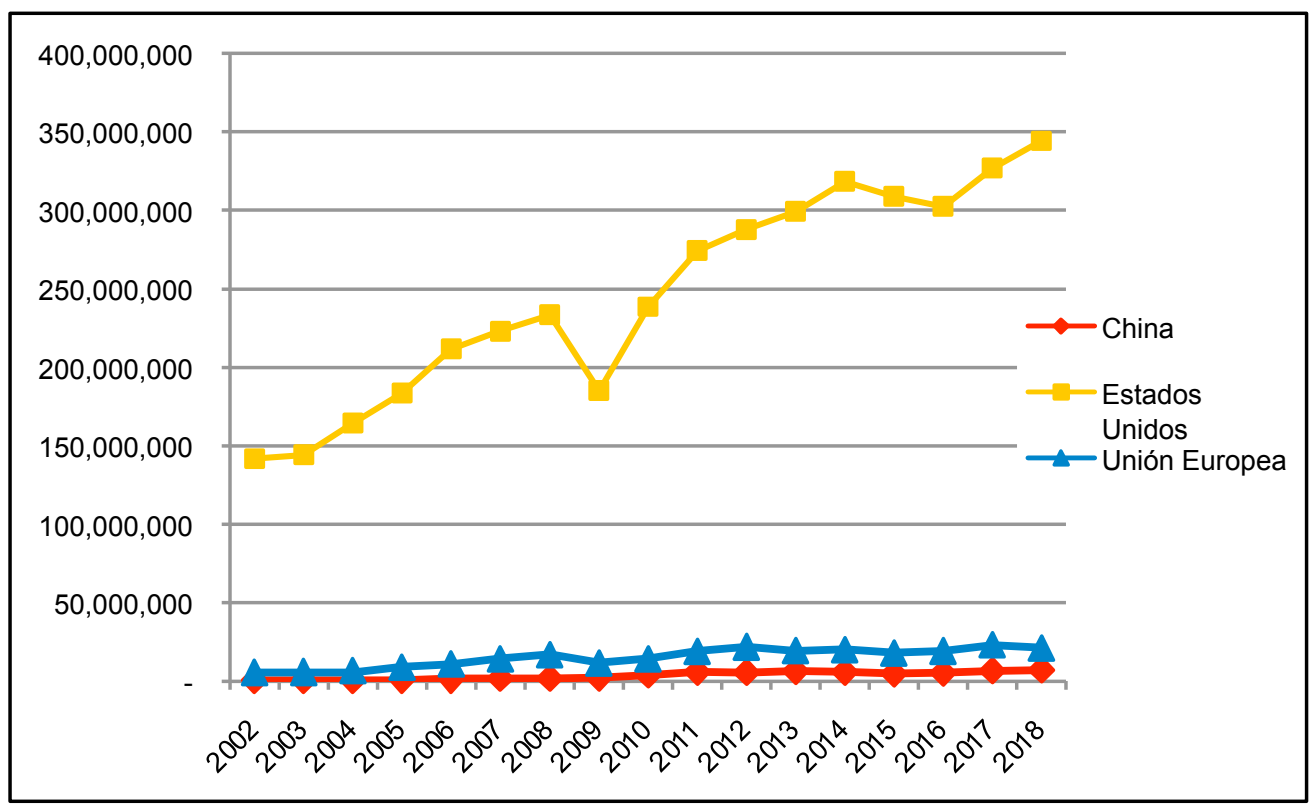

*Valores en miles de U\$S

Fuente: Elaboración propia a partir de información del Sistema de Información de Comercio Exterior (SICOEX) - ALADI.

${ }^{8}$ El USMCA (United States, Mexico and Canada Agreement), denominado en México como T-MEC (Tratado entre México, Estados Unidos y Canadá) es el resultado del proceso de renegociación del NAFTA (North American Free Trade Agreement) que los tres países miembros iniciaron en el año 2017 y que entró en vigor el 1 de julio de 2020. 
Gráfica 6. Importaciones totales de México desde China, Estados Unidos y la Unión Europea, años 2002-2018

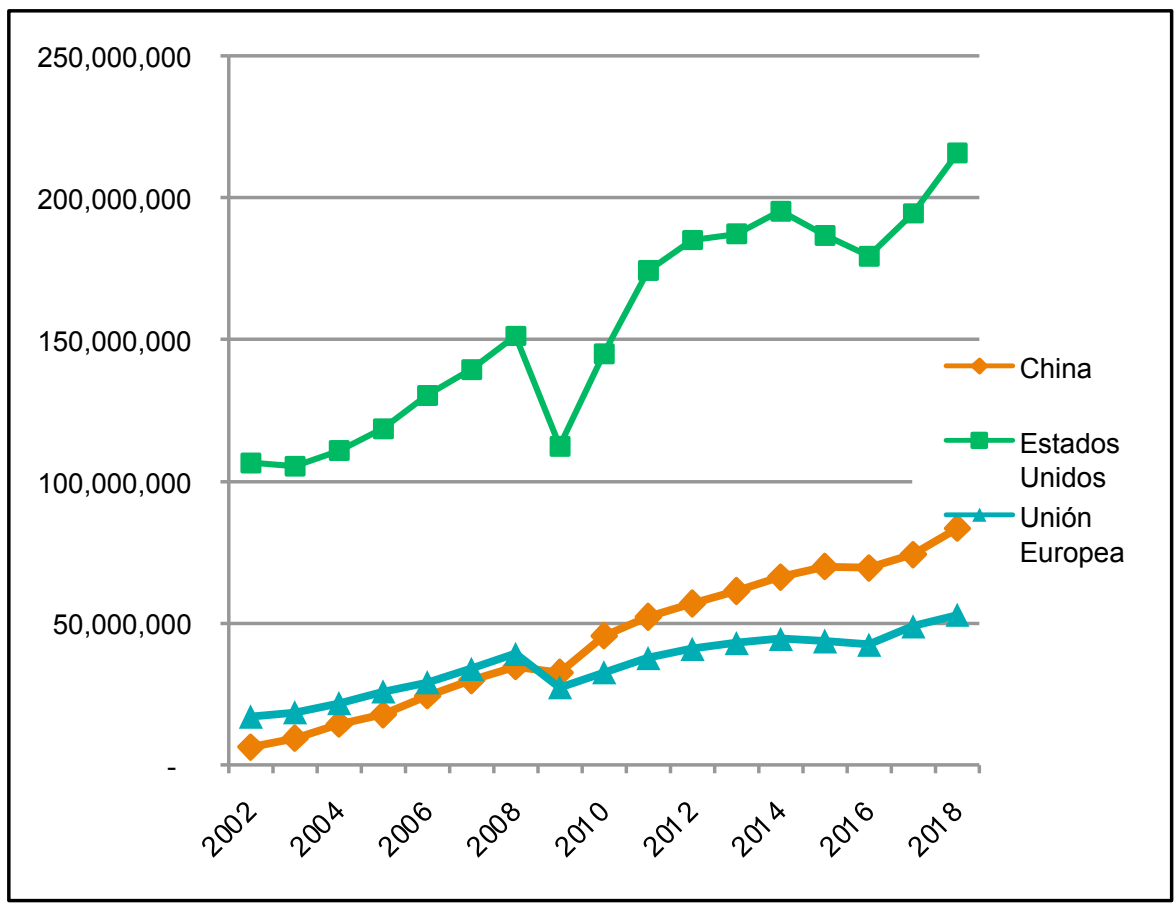

*Valores en miles de U\$S

Fuente: Elaboración propia a partir de información del Sistema de Información de Comercio Exterior (SICOEX) - ALADI.

Gráfica 7. Exportaciones totales de Colombia hacia China, Estados Unidos y la Unión Europea, años $2002-2019$

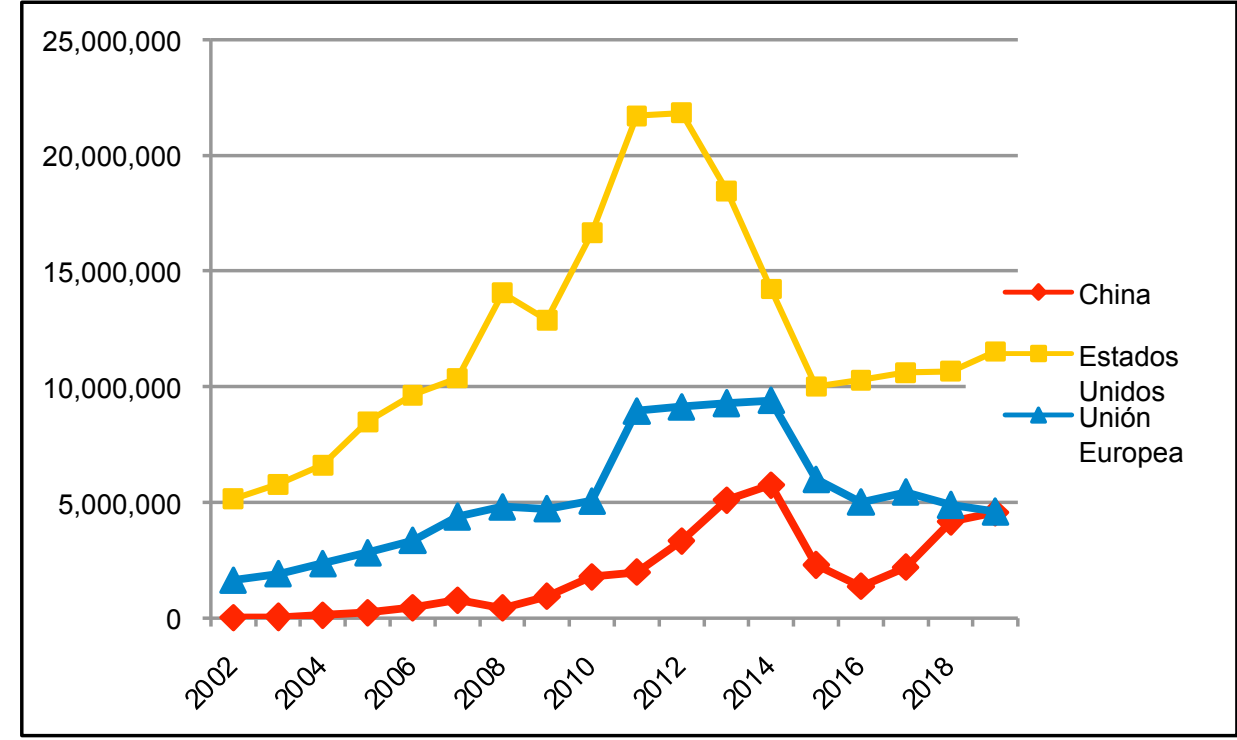

*Valores en miles de U\$S

Fuente: Elaboración propia a partir de información del Sistema de Información de Comercio Exterior (SICOEX) - ALADI. 


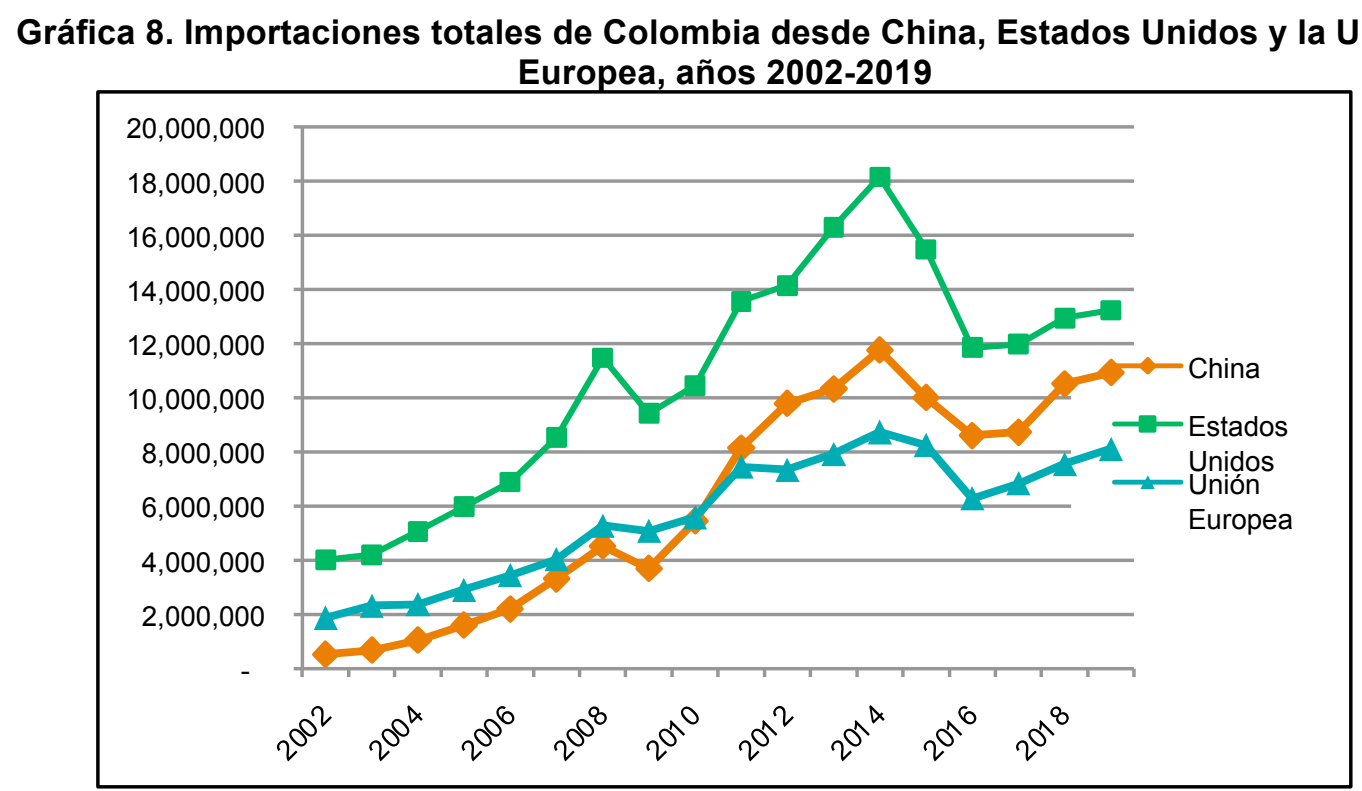

*Valores en miles de U\$S

Fuente: Elaboración propia a partir de información del Sistema de Información de Comercio Exterior (SICOEX) - ALADI.

La misma dinámica es encontrada en el caso colombiano (Gráficas 7 y 8), con la diferencia de que, tanto en las exportaciones como en las importaciones, la distancia o el volumen de comercio entre Estados Unidos y China presenta una tendencia de caída, o sea, hay un crecimiento en la importancia china.

Inicialmente, podríamos suponer que la participación de México en la AP posibilitaría una intensificación de las relaciones entre esos países y los EUA debido a su participación en el USMCA y por la existencia del Tratado Integral y Progresista de Asociación Transpacífico (CPTPP por sus siglas en inglés), en el cual también participan Chile, México y Perú. No obstante, la elección de Donald Trump como presidente norteamericano alteró esa lógica, sea porque éste tuvo como uno de sus primeros actos en el mando de la presidencia de los EUA, la retirada del país del CPTPP, antes denominado Tratado Integral y Progresivo de Asociación transpacífico (TPP por sus siglas en inglés), y su presión durante el proceso de renegociación del NAFTA que parece aumentar aún más las animosidades entre los aliados, incluso con la presión del presidente Trump amenazando acabar con el acuerdo y para sustituirlo por acuerdos bilaterales con México y Canadá.

Además de las amenazas, el punto a ser destacado en esta argumentación es que la actual política externa norteamericana se está distanciando de América Latina y aumentando el 
grado de desconfianza de esos países con relación a su alianza con los EUA, estimulando una rearticulación con otras regiones, que ha resultado ventajosa para la UE pero principalmente para China que se consolida como principal aliado de Chile y Perú y gana importancia junto a Colombia (Gráficas 9 y 12).

\section{Gráfica 9. Exportaciones totales de Chile hacia China, Estados Unidos y la Unión Europea,} años 2002 - 2019

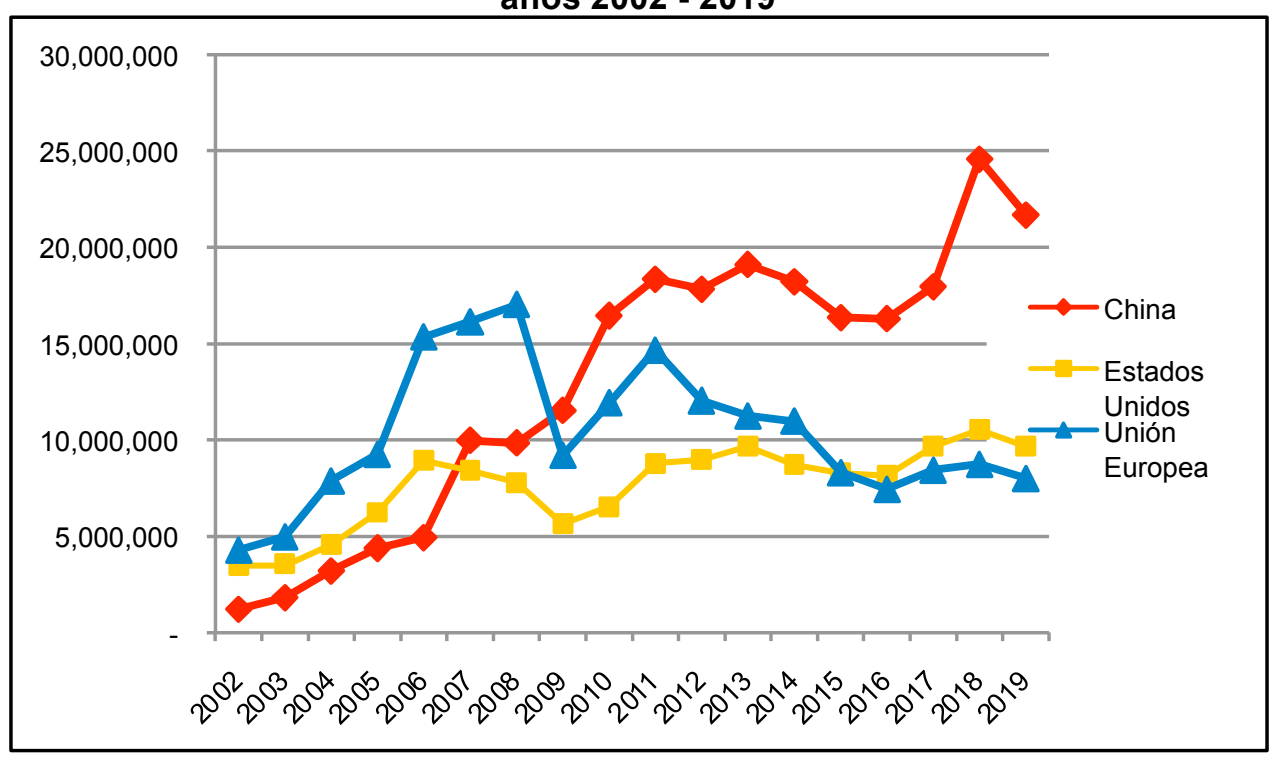

*Valores en miles de U\$S

Fuente: Elaboración propia a partir de información del Sistema de Información de Comercio Exterior (SICOEX) - ALADI.

\section{Gráfica 10. Exportaciones totales de Perú hacia China, Estados Unidos y la Unión Europea,} años $2002-2019$

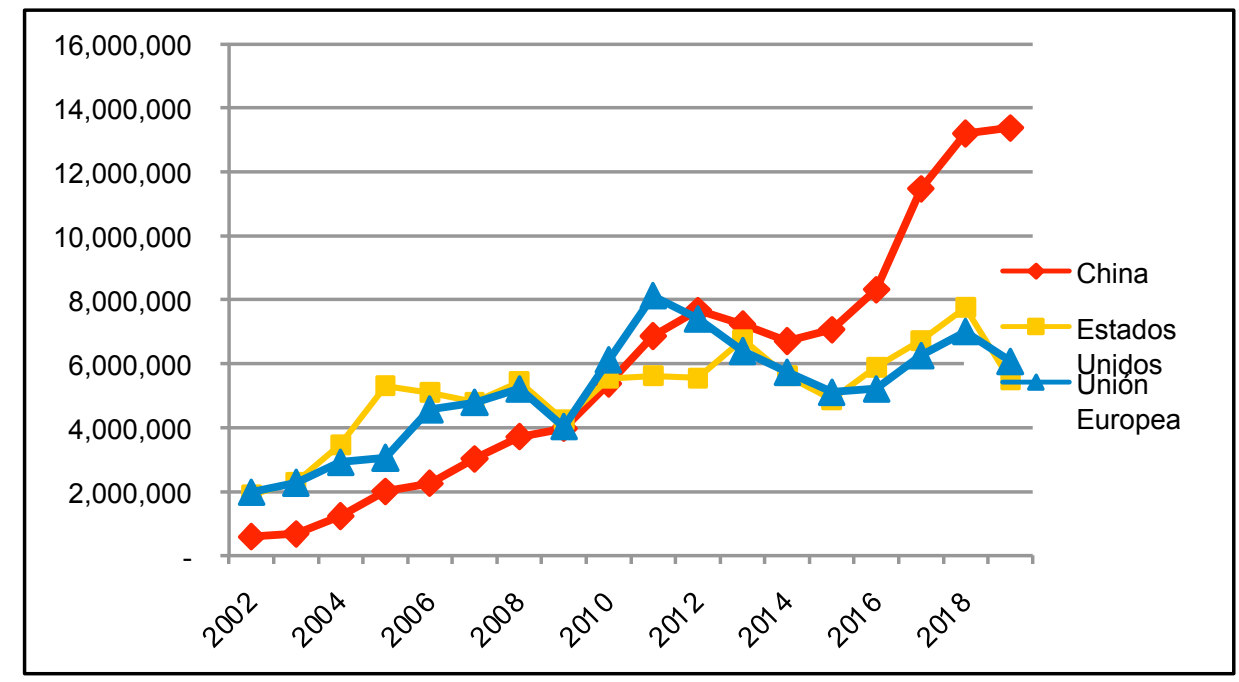

*Valores en miles de U\$S 
Karina Lilia Pasquariello Mariano

Relaciones de los procesos de integración de América Latina con la Unión Europea, entre el diálogo político, los programas de cooperación y los acuerdos comerciales. DOI: https://doi.org/10.24215/24689912e031

Fuente: Elaboración propia a partir de información del Sistema de Información de Comercio Exterior (SICOEX) - ALADI.

\section{Gráfica 11. Importaciones totales de Chile desde China, Estados Unidos y la Unión Europea, años $2002-2019$}

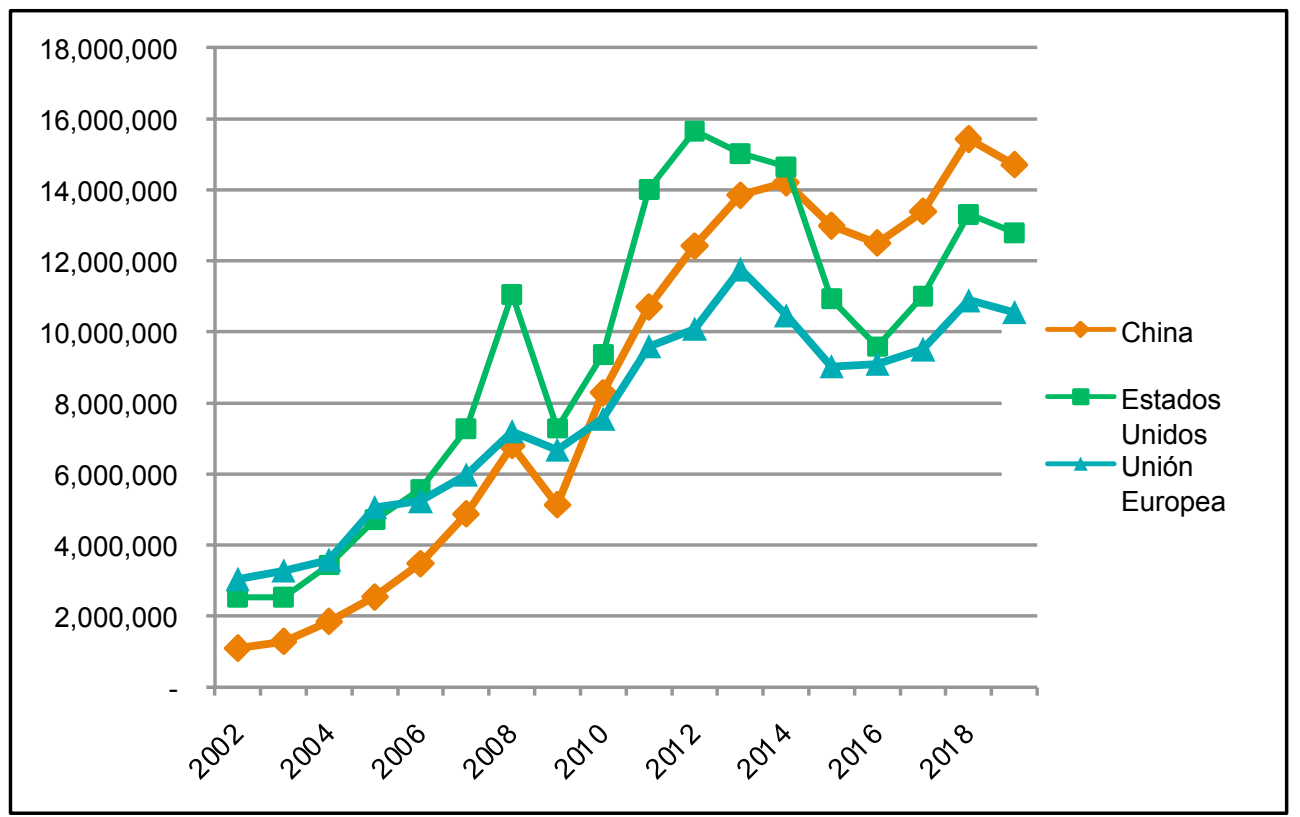

*Valores en miles de U\$S

Fuente: Elaboración propia a partir de información del Sistema de Información de Comercio Exterior (SICOEX) - ALADI.

Gráfica 12. Importaciones totales de Perú desde China, Estados Unidos y la Unión Europea, años $2002-2019$

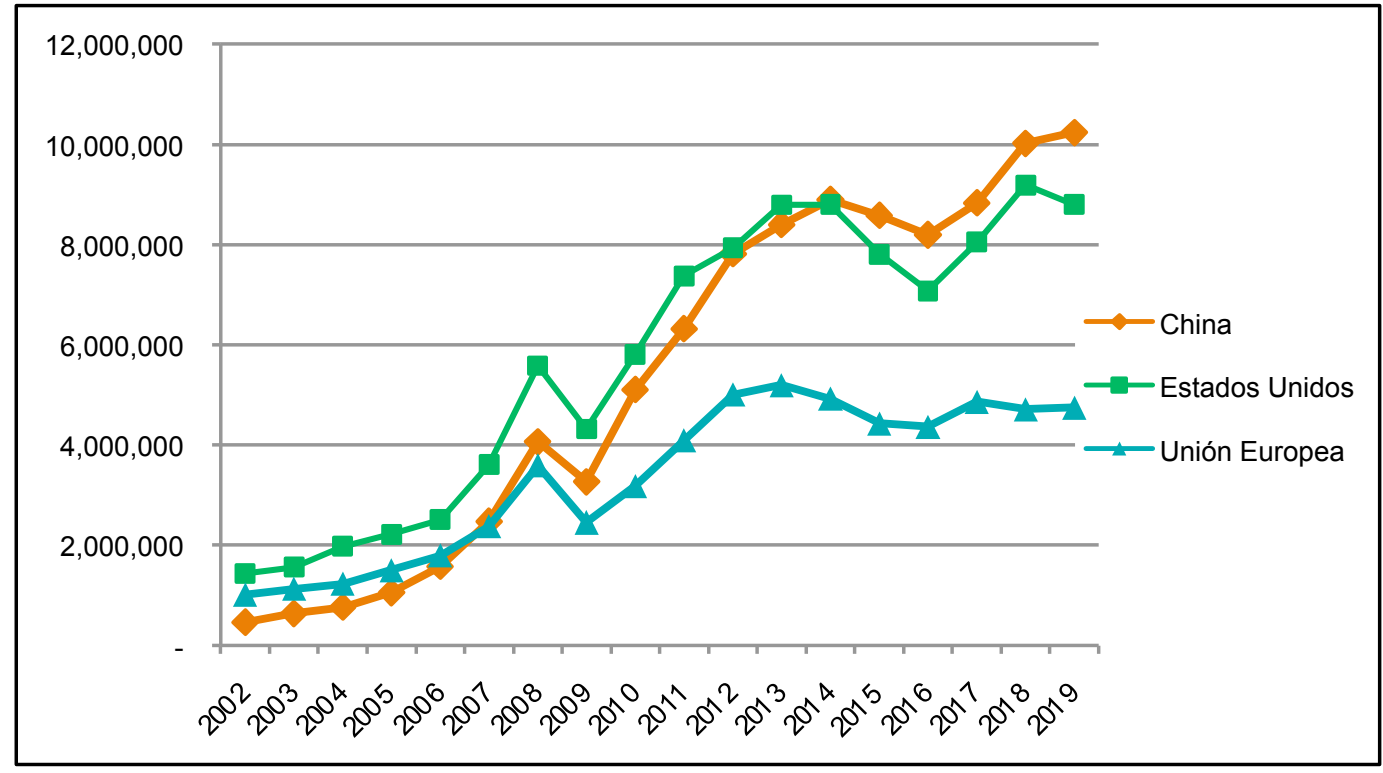

*Valores en miles de U\$S

Fuente: Elaboración propia a partir de información del Sistema de Información de Comercio Exterior (SICOEX) - ALADI. 
China ha experimentado un crecimiento económico sin precedentes en las últimas décadas con lo cual se ha puesto en un lugar ventajoso dentro del sistema económico internacional; la prosperidad de su comercio le ha permitido inserirse en la lógica de libre comercio bajo las reglas internacionales (Yin-Shi, 2013). Este país asiático se ha planteado consolidar socios comerciales que le permitan tener acceso a la extracción de recursos para cubrir la demanda energética y alimentaria, por lo cual no basa sus relaciones comerciales en afinidad política.

Las relaciones birregionales entre China y ALC están fundamentadas en la reprimarización de la economía para lo cual se han negociado TLC enfocados al acceso de materias primas básicas, lo que en el corto plazo beneficia a la región de $A L C$ en la medida que en las negociaciones con China no se profundizan aspectos políticos ni de cooperación al desarrollo, facilitando el acceso a inversión extranjera directa para la explotación de recursos naturales.

\section{CONCLUSIÓN}

El análisis de los tres casos muestra que la UE es un aliado importante de ALC, buscando consolidarse no solamente como un referente de integración regional, sino también de valores (a partir del universalismo europeo) y en la construcción de una entidad diferenciada con relación a los EUA y a Asia (Sanahuja, 2013). Esta influencia europea es sustentada históricamente por el proceso de colonización, pero principalmente por la estrategia más reciente del bloque europeo de buscar la construcción de una gobernanza de la globalización sobre una matriz europea, reforzando su papel de liderazgo dentro del sistema internacional.

Sin embargo, esta preponderancia de valores ha sufrido en la última década una competencia no de otros valores, sino de intereses más pragmáticos que han desplazado la atención de los países de la ALC para el Pacífico. Cuando consideramos las relaciones entre ALC y UE notamos que el aumento de la influencia asiática estuvo acompañado por la intensificación del interés europeo en concluir los acuerdos comerciales, poniendo en un segundo plano las cuestiones políticas. Sin embargo, esa estrategia no fue suficiente para revertir la tendencia de disminución de la importancia europea en la región, en el aspecto económico. 
China está consolidándose como el principal aliado comercial de la región, así como país inversionista y financiador del desarrollo de las economías de ALC. De esta manera, su influencia se expande en la región, especialmente por su estrategia de no condicionar las relaciones comerciales a las asimilaciones de valores, como lo hacen la UE y los EUA, que buscan incorporar en las negociaciones comerciales la agenda OMC-plus, marcada por nuevos principios reguladores del comercio mundial.

Además, existe una percepción más positiva en las relaciones con China porque se entiende esa alianza como dentro de una cooperación Sur-Sur, y no a partir de una relación de desequilibrio norte-sur, como en el caso de las negociaciones con la UE. Esta cuestión de percepción es importante porque ha facilitado la celebración de acuerdos entre los países de ALC y China, en cuanto en el caso de la UE estos se han negociado durante décadas en algunos casos (como el del MERCOSUR).

El caso del MERCOSUR es interesante porque apunta una contradicción. De un lado, la recusa europea en firmar el acuerdo por razones ambientales, refuerza la perspectiva de que las relaciones en este caso no son meramente comerciales y que Europa ejerce un rol importante en el establecimiento de padrones internacionales de comportamiento. Al mismo tiempo, no concretar el acuerdo podría significar un distanciamiento todavía mayor en relación con ALC, dejando de ser un importante interlocutor e influencia para los procesos regionales.

El actual contexto de cambio político en América del Sur principalmente indica que habrá espacio para alterar las relaciones entre UE y ALC, aunque se mantenga la tendencia de consolidación de China como principal aliado. Esto dependerá mucho de cómo los EUA encaminen su política para la región y de los posibles cambios políticos que podrán ocurrir en 2021.

\section{REFERENCIAS BIBLIOGRÁFICAS}

Acordo-Quadro de Cooperação Inter-regional entre a Comunidade Europeia e seus Estados Membros, por uma Parte, e o Mercado Comum do Sul e seus Estados Parte, por Outra. (1995). Madrid. content/PT/TXT/PDF/?uri=CELEX:21996A0319(02)\&from=PT

http://eur-lex.europa.eu/legal-

Alianza del Pacifico. (2019). Declaración Conjunta sobre una asociación entre los Estados Parte del Acuerdo Marco de la Alianza del Pacífico y la Unión Europea. Nueva York, 25 sep. https://alianzapacifico.net/download/declaracion-conjunta-sobre-una-asociacion-entre-losestados-parte-del-acuerdo-marco-de-la-alianza-del-pacifico-y-la-union-europea/\# 
Asociación Latinoamericana de Integración-ALADI. (s.f.). Sistema de Información de Comercio Exterior. Totales de Comercio Exterior. Montevideo. http://consultawebv2.aladi.org/sicoexV2/jsfComercio/comercio_exterior_Entrada.seam?cid=1 401367

Ayuso, A., Susanne, G.y Serbin, A. (2018). América Latina y el Caribe y la Unión Europea ante la globalización y la gobernanza global. En A. Serbin, y A. Serbin Pont, (Coords.), ¿Por qué la Unión Europea debería ser de relevancia para América Latina y el Caribe? (pp. 313).Fundación EU-Lac; CRIES. https://eulacfoundation.org/es/system/files/relevcia-ue-laces-web.pdf

Bispo dos Santos, L. (2018). As negociações do Acordo de Associação Inter-regional Mercosul e União Europeia: o posicionamento dos grupos agrícolas e industriais de Argentina e Brasil. [Tesis de Maestría Programa de Posgrado em Relaciones Internacionales San Tiago Dantas (UNESP, UNICAMP e PUC-SP)]. Repositorio Institucional UNESP. https://orcid.org/0000-0002-4559-918X

Cavalcanti, F. G. y Trein, F. (2007). Uma análise crítica do acordo de associação estratégica entre a União Europeia e a América Latina e o Caribe - A Cúpula de Viena. Revista Brasileira de Política Internacional, 60(1), https://www.scielo.br/pdf/rbpi/v50n1/a04v50n1

Conejero, D. (2012). Cooperación Unión Europea - Comunidad Andina. [Tesis de Maestría en Cooperación Internacional y Gestión de Proyectos por la Fundación Ortega y Gasset Gregorio

https://iecah.org/images/stories/Cooperacion_UE_con_la_Comunidad_Andina.pdf Marañón].

EI Telégrafo. (2006,11 de noviembre). Ecuador y UE firman hoy un histórico acuerdo. http://tinyurl.com/y8fx298t

Fairlie Reinoso, A. (2010). Del Acuerdo de Asociación entre la Unión Europea y la Comunidad Andina (CAN) al Acuerdo Comercial Multipartes con Colombia y Perú: ¿Qué escenarios para la integración regional? Observatorio Social de las Relaciones Unión Europea - América Latina; Asociación Latinoamericana de Organizaciones de Promoción al Desarrollo A.C.-ALOP. https://eulacfoundation.org/es/content/del-acuerdo-deasociaci\%C3\%B3n-entre-la-uni\%C3\%B3n-europea-y-la-comunidad-andina-can-al-acuerdo

Fundación Unión Europea-América Latina y el Caribe - Fundación EU-LAC. (2017). Vademécum sobre Programas de Cooperación de la UE con ALC (Traducción: S. Calaveras).

https://eulacfoundation.org/es/system/files/vademecum programas cooperacion ue lac.pdf

Gómez Cordero, L. D. (2015). Relaciones entre la Unión Europea y América Latina: viejos desafíos, nuevas estrategias [Trabajo de Grado Pontifica Universidad Javeriana]. Repositorio de la Pontifica Universidad Javeriana. https://repository.javeriana.edu.co/handle/10554/20581

Hänggi, H., Roloff, R. y Rüland, J. (2006). Interregionalism and International Relations (1ra. Ed.). Routledge. 
La Nación. (2020, 7 de octubre). El Parlamento Europeo convalidó un informe contrario al acuerdo con el MERCOSUR. https://www.lanacion.com.ar/el-mundo/el-parlamento-europeoconvalida-informe-criticando-estado-nid2472657

Leví Coral, M. (2010). La relación UE-Comunidad Andina en el contexto de la negociación de los acuerdos de asociación. En J. Roy y R. Dominguez, (Eds.). España, la Unión Europea y la Integración latinoamericana (pp. 247-265). Miami-Florida European Union Center/Jean Monnet Chair. https://eulacfoundation.org/es/content/espa\%C3\%B1a-en-la-uni\%C3\%B3neuropea-y-el-estado-de-la-integraci\%C3\%B3n-latinoamericana

MERCOSUR. (2019, 28 de junio). MERCOSUR cierra un histórico Acuerdo de Asociación Estratégica con la Unión Europea. https://www.MERCOSUR.int/MERCOSUR-cierra-unhistorico-acuerdo-de-asociacion-estrategica-con-la-union-europea/

Molina del Pozo, C. F. y Mata Diz, J. B. D. (2010). Repensando la Asociación Estratégica UE-América Latina: Algunas reflexiones para el afinamiento de las relaciones birregionales. Roy, J. y Dominguez, R. (Eds.). España, la Unión Europea y la Integración latinoamericana. pp. 131-152. Miami-Florida European Union Center/Jean Monnet Chair. https://eulacfoundation.org/es/system/files/Repensando\%20la\%20Asociaci\%C3\%B3n\%20Es trat\%C3\%A9gica\%20UE-AL.pdf

Müller, G. G., Wouters, J., Defraigne, J. C., Santander, S. y Raube, K. (2017). Estudio La Asociación Estratégica UE-América Latina: situación actual y caminos futuros. Departamento Temático, Dirección General de Políticas Exteriores. Parlamento Europeo : https://doi.org/10.2861/53020

Parra Santamaría, A. (2010). El interregionalismo europeo y la integración regional latinoamericana. $\quad$ Entramado, 6(2), 96-106. https://www.redalyc.org/articulo.oa?id=265419645007

Paquariello Mariano, K. L. y Correa Neto Ribeiro, C. (2017). Regionalismo e democracia: a participação nos processos de integração na América do Sul. Em A. L. Reis da Silva y E. Munhoz Svartman, (Orgs.). Inserção internacional da Argentina e do Brasil. Desafios da Política Externa e de Defesa Editora da UFRGS

Paquariello Mariano, K. L. y Leite Araujo, A. (2020). Os limites institucionais das presidências do Mercosul e da União Europeia diante do acordo comercial. En: Soares, A.; Paz Neves, L. y Themoteo, R. J. (Orgs.). O novo acordo Mercosul-União Europeia em perspectiva. (pp. 59-77). Konrad Adenauer Stiftung. https://www.kas.de/documents/265553/265602/Serie+Brasil+-+Europa.pdf/42df1152-348f$\underline{\mathrm{f} 47 \mathrm{~b}-24 \mathrm{ed}-088 \mathrm{ec} 088 \mathrm{f073} \text { ?version }=1.0 \& \mathrm{t}=1595362750767}$

Quevedo Flores, J. (2007). El interregionalismo Unión Europea- América Latina y el Caribe: claves para la construcción de un sistema multilateral. InterSciencePlace, vol. 1, n. 2. ISSN: 1679-9844. http://www.interscienceplace.org/isp/index.php/isp/article/view/19

Sanahuja, J. (2006). Hacia el logro de un verdadero multilateralismo en las relaciones entre la Unión Europea y América Latina., Parlamento Europeo, Direccion General de Politicas Exteriores Departamento temático. https://eulacfoundation.org/es/system/files/Hacia\%20el\%20logro\%20de\%20un\%20verdadero 
\%20multilateralismo\%20en $\% 20$ las $\% 20$ relaciones $\% 20$ entre $\% 20 l a \% 20$ Uni\%C3\%B3n $\% 20$ Eur opea $\% 20 \mathrm{y} \% 20 \mathrm{Am} \% \mathrm{C} 3 \%$ A9rica\%20Latina.pdf

Sanahuja, J. (2013). La Unión Europea y el Regionalismo Latinoamericano: un balance. Revista Investigación \& Desarrollo, 21(1), 156-184. https://www.redalyc.org/pdf/268/26828624007.pdf

Serbin, A.; y Serbin Pont, A. (Coord.). (2018). ¿Por qué la Unión Europea debería ser de relevancia para América Latina y el Caribe? Fundación EU-Lac; CRIES. https://eulacfoundation.org/es/system/files/relevcia-ue-lac-es-web.pdf

Sistema de Información sobre Comercio Exterior-SICE. (2020). MERCOSUR-Unión Europea. Antecedentes y negociaciones. Política Comercial: Novedades OEA.. http://www.sice.oas.org/TPD/MER EU/MER EU s.asp\#: :text=El\%20MERCOSUR\%20y\%2 0la\%20Uni\%C3\%B3n,0\%20de\%20julio\%20de\%201999

Vogel, B. (2007). Prólogo. En: G. Wahlers, (Ed.). América Latina y la Unión Europea. (pp. 710). Fundación Konrad

Adenauer. https://www.kas.de/c/document_library/get_file?uuid=27f59d65-76ae-5eaa-c76a569995547 c30\&groupld $=252038$

Yin-Shi, W. (2013). La política de Estados Unidos, Unión Europea y China con respecto a América Latina: resultados y perspectivas en la integración económica global (1990-2010). [Tesis Doctora Universidad Complutense de Madrid]. Repositorio de la UCM. http://eprints.ucm.es/20061/

ANA MARía SuÁRez Romero: Estudiante de doctorado del Programa de Postgrado en Ciencias Sociales de la Universidad Estatal Paulista "Júlio de Mesquita Filho" - UNESP, campus AraraquaraBrasil, y Magíster del Programa de Postgrado en Relaciones Internacionales San Tiago Dantas (UNESP / UNICAMP / PUC-SP) en 2015. Integrante del Grupo de Estudio Interdisciplinario sobre Cultura y Desarrollo (GEICD) y del Observatorio del Regionalismo (ODR) vinculado a la Red de Investigación en Política Exterior y Regionalismo (REPRI). E-mail: a.romero@unesp.br.

KaRina Lilia PAsquariello MARIANo: Profesora de la Facultad de Ciencias y Letras de la Universidad Estatal Paulista "Júlio de Mesquita Filho" - UNESP, campus Araraquara-Brasil. Coordinadora del Grupo de Estudio Interdisciplinario sobre Cultura y Desarrollo (GEICD) y Coordinadora de la Red Development, International Politics and Peace (DIPP) del Programa de Postgrado en Relaciones Internacionales San Tiago Dantas (UNESP-UNICAMP y PUC/SP). Investigadora de la Red de Investigación en Política Externa y Regionalismo (REPRI). E-mail: karina.mariano@unesp.br.

Fecha de recepción: 1/11/2020

Fecha de aceptación: 29/11/2020 